\title{
«Un espejo para las mujeres»: el romance de Griselda (del medievo al siglo XVIII)
}

\author{
Juan Gomis Coloma
}

Institut Universitari d'Estudis de la Dona (Universidad de Valencia)

Resumen

En el siglo XVIII, los pliegos de cordel invadieron las calles y plazas de España al grito de ciegos recitadores que los cantaban y vendían. Sus historias, además de proporcionar entretenimiento y diversión, ofrecían a su numeroso público modelos de comportamientoo normas imitables que pudieron influir de un modo u otro en la regulación de sus conductas. Este trabajo es una aportación al estudio de la cultura popular en esta dirección, y para ello se centra en el análisis del romance de Griselda. Relato original del Decamerón de Boccaccio, difundido por toda Europa a partir de la traducción latina de Petrarca, la comparación entre la Griselda romanceada y sus versiones castellanas anteriores permite comprobar las novedosas aportaciones que presenta el pliego del siglo xVIII que fijan su mensaje orientándolo hacia la difusión de un determinado modelo conyugal en el que Griselda es ejemplo de extremada paciencia y devota sumisión para las mujeres casadas. Una mirada general a los romances divulgados en esta época confirma la existencia de más textos cuya finalidad era inculcar esos mismos valores entre las mujeres. Dado el contraste existente entre este modelo familiar (tradicional y misógino) y el discurso ilustrado sobre la familia sentimental que se desarrolló en la misma época, el estudio del romance de Griselda y de las ideas y actitudes que pretendió inculcar resulta tanto más interesante para profundizar en la interacción y desarrollo de modelos familiares tan dispares en un tiempo de cambios profundos.

Palabras clave

Griselda. Boccaccio. Romance. Literatura de cordel. Mujer. Matrimonio. CES.XVIII, núm. 16 (2006), págs. 89-112. 
Por fortuna, la literatura de cordel no constituye hoy un objeto de estudio novedoso: existen excelentes trabajos, algunos de ellos ya clásicos, que se sumergieron en ese océano revuelto que representa el conjunto de los pliegos para recopilar, ordenar e identificar impresos desperdigados por los fondos de bibliotecas y de archivos. El esfuerzo es tanto más encomiable por cuanto superó el desprecio secular que los pliegos habían inspirado a las elites intelectuales, dado el ínfimo valor literario que les asignaban y los contenidos detestables que a su juicio difundían ${ }^{1}$. Recuperando por tanto la literatura de cordel como objeto digno de investigación, los trabajos se orientaron hacia diferentes objetivos: la elaboración de catálogos de pliegos para facilitar la localización de los textos por parte del investigador (cuyo impulso fundamental correspondió a Antonio Rodríguez-Moñino) $)^{2}$, el estudio sobre la producción y difusión de los impresos ${ }^{3}$, o el análisis de los diversos temas plasmados en los romances ${ }^{4}$. La labor, ardua y fructífera, iluminó una parcela de la producción literaria ignorada y menospreciada hasta entonces y sentó las bases para las futuras investigaciones.

Este texto es una pequeña aportación más al estudio de la literatura de cordel y persigue, sin querer ser pretencioso, ofrecer un enfoque distinto que amplíe las posibilidades que encierran los pliegos como fuente histórica. Aunque hace ya tiempo que la noción de fuente histórica se amplió sobrepasando los estrechos márgenes de la sala de archivo y en consecuencia los textos literarios son por lo común considerados hoy en día valiosos recursos para la labor del historiador, la literatura de cordel permanece casi en la oscuridad para la historiografía española. Teniendo en cuenta la amplísima difusión con que contó este enorme conjunto de impresos (especialmente en el siglo XVIII, el período que nos interesa

1 Así, en el siglo XIX, un colector de romances como Agustín Durán se referiría a ellos, paradójicamente, como «este cenagal de corrupción, de falsa ciencia y fe extraviada», citado en Julio Caro Baroja, Ensayo sobre la literatura de cordel, Istmo, Madrid, 1990, pág. 21.

2 Antonio Rodríguez-Moñino, Diccionario bibliográfico de pliegos sueltos poéticos (siglo XVI), Madrid, Castalia, 1970; los catálogos de María Cruz García de Enterría de los pliegos del British Museum, Biblioteca Pública Municipal de Oporto, Biblioteca Nacional de Viena, las universitarias de Pisa y Gotinga, Biblioteca de Cracovia, Biblioteca del Estado de Baviera, de Munich y la Ambrosiana de Milán, todos ellos en la colección «Joyas Bibliográficas»; Manuel Alvar, Romances en pliegos de cordel (siglo XVIII), Málaga, Ayuntamiento, 1974; Francisco Aguilar Piñal, Romancero popular del siglo XVIII, Madrid, CSIC, 1972, entre otros.

3 Por ejemplo, los magníficos estudios de François LoPEz: su capítulo «Industria y comercio» en Víctor Infantes, François LoPEZ y Jean-François Botrel, Historia de la edición y de la lectura en España (1472-1914), Madrid, Fundación Germán Sánchez Ruipérez, 2003, págs. 328-367; «La difusión de la literatura popular en el Antiguo Régimen», en Agustín Escolano (dir.), Leer y esribir en España. Doscientos años de alfabetización, Madrid, Pirámide, 1992, págs. 275-284; Jean-François BотREL, Libros, prensa y lectura en la España del siglo XIX, Madrid, Pirámide, 1993.

4 Véase, entre otros, Caro Baroja, ibid.; María Cruz García de Enterría, Sociedad y poesía de cordel en el Barroco, Madrid, Taurus, 1973; Joaquín MARCo, Literatura popular en España en los siglos XVIII y XIX, Madrid, Taurus, 1977; María José Rodríguez SÁnchez de León, «Literatura popular», en Aguilar Piñal (ed.), Historia literaria de España en el siglo XVIII, Madrid, Trotta, 1996, págs. 327-367. 
aquí) y su indudable influencia en el imaginario de una gran parte de la población española, el llamado «vulgo» (para el que los romances constituían uno de los pocos medios de acceso a la letra impresa), este vacío requiere ser atendido por el historiador interesado en estudiar el complejo ámbito de la cultura popular, a sabiendas de la problemática que encierra este concepto ${ }^{5}$.

Proponemos un estudio de la literatura de cordel desde una perspectiva alternativa al «materialismo»y a la «mentalidad»: que vaya más allá del mero rastreo a la búsqueda de datos sobre la cultura material de la sociedad (que son, por cierto, muy abundantes en los pliegos), y que a la vez no aspire descubrir en los romances la visión del mundo o mentalidad de los lectores «populares» que se les supone. Siguiendo la línea de Roger Chartier ${ }^{6}$, sostenemos que estos textos, además de divertir y entretener, ofrecían a sus lectores un repertorio de modelos de comportamiento, un conjunto de representaciones que eran también normas imitables, y desde esta perspectiva deben ser leídos por el historiador, profundizando en la interacción entre esos modelos de comportamiento propuestos por los romances y el espacio de recepción y apropiación de los textos por parte de sus lectores, entre la representación y la práctica, teniendo siempre en cuenta la pluralidad y movilidad de significados asignados a un mismo texto por públicos diferentes.

Para ello queremos centrarnos en el romance de Griselda. Como es bien sabido, esta historia narra las pruebas a las que el marqués de Saluzo somete a su virtuosa esposa, Griselda, para comprobar su fidelidad y constancia. Las razones de la elección de este texto son tres: en primer lugar, su largo recorrido a través de los siglos y de la geografía europea. La historia de Griselda fue incluida por Boccaccio como novela décima en la última jornada del Decamerón (sin que todavía se sepa con certeza si fue invención del florentino o inspirada en la tradición oral), y conoció en los siglos posteriores una difusión extraordinaria por Europa: España, Portugal, Francia, Inglaterra, Irlanda, Alemania, Dinamarca, Polonia, Islandia..., conocemos versiones de la novela en casi todos los países europeos y en variados géneros literarios y artísticos (del cuento a la ópera, pasando por

5 Para una aproximación a la complejidad que encierra el término «cultura popular»,véase Roger Chartier, Culture populaire. Retour sur un concept historiographique, Valencia, Eutopías, 1994; Jacques REvel, «La culture populaire: sur les usages et les abus d' un outil historiographique», en Culturas populares. Diferencias, divergencias, conflictos, Actas del coloquio celebrado en la casa de Velázquez (nov.dic. 1983), Madrid, Casa Velázquez/Univ. Complutense; Peter Burke, La cultura popular en la Europa moderna, Madrid, Alianza, 1996, págs. 17-142; Carlo GinZBurg, El queso y los gusanos. El cosmos según un molinero del siglo XVI, Barcelona, Península. 2001, págs. 9-20; Michel de CerTEaU, La culture au pluriel, París, Seuil, 1993.

6 Roger CharTiER, «Introduction», en Roger CharTiER y Hans-Jürgen LüSEBrink (dirs.), Colportage et lecture populaire. Imprimés de large circulation en Europe XIe-XIXe siècles, Actes du colloque des 21-24 avril 1991, Wolfenbüttel, págs. 11-18; CHARTIER, Culture populaire. Retour sur un concept historiographique. 
el teatro $)^{7}$. Se ha llegado a afirmar, de hecho, que Griselda es el cuento que más fortuna ha tenido en otras literaturas ${ }^{8}$.

Esta trayectoria secular nos permite, centrándonos en la Griselda romanceada del siglo XVIII, intentar rastrear las diferentes lecturas y usos que la misma historia tuvo en España según las épocas, comparando las estrategias textuales y el soporte tipográfico del pliego con los de otras versiones anteriores, de las que por otra parte se nutrió sin duda el autor (anónimo) del romance.

En segundo lugar, el éxito de la historia en el siglo XVIII fue grande a juzgar por el número de ediciones: nosotros utilizaremos un ejemplar de la imprenta de Agustín Laborda conservado en la Biblioteca Serrano Morales de Valencia9 pero hemos identificado otras dos ediciones distintas en la Biblioteca Nicolau Primitiu de la misma ciudad, una por Cosme de Granja (Valencia) y otra del siglo XIX, por Marés y Compañía (Madrid) ${ }^{10}$. Francisco Aguilar Piñal identificó dos ediciones por Fausto García Tena (Córdoba), otra por Santaren (Valladolid) y otra más sin pie de imprenta. Agustín Durán incluyó también este texto en su colección de romances y aunque lo dató en la segunda mitad del siglo XVII no informó de qué imprenta salió su ejemplar. En su estudio sobre la literatura popular, Joaquín Marco se refirió a su vez a la gran popularidad de la historia ${ }^{11}$. A falta de una recopilación exhaustiva, parece claro que el romance de Griselda se reimprimió de continuo entre mediados del siglo XVII y la primera mitad del XIX. Esta preferencia de la que al parecer gozó por parte del público nos proporciona un suelo más firme para adentrarnos en el resbaladizo mundo de los pliegos de cordel y de la literatura popular en general: no estamos hablando de una narración cualquiera, sino de una con fuerte arraigo en la literatura peninsular y que, más aún, en forma de pliego constituyó en el siglo XVIII casi un «clásico» entre los romances que los ciegos cantaban y vendían por las calles.

Tercera razón: según el planteamiento de la Griselda romanceada, la narración constituía un ejemplo para que las esposas aprendieran a ser pacientes y abnegadas con sus maridos, basando la prosperidad conyugal en el cumpli-

7 Para la difusión de Griselda por Europa, véase de Raffaele Morabito (ed.), La circolazione dei temi e degli intrecci narrativi: il caso Griselda, Atti del convegno di studi, L'Aquila, 3-4 diciembre 1986, Japadre, L’Aquila-Roma, 1988; (ed.), La storia di Griselda in Europa, Atti del Convegno: Modi dell'intertestualità: la storia di Griselda in Europa, L'Aquila, 12-14 maggio 1988, Japadre, L' Aquila-Roma, 1990.

8 Cit. en Isidoro Pisonero del Amo, «Un motivo boccacciano: «La paciente Griselda» en la literatura española», en Homenaje a Alonso Zamora Vicente III. 2 Literatura española de los siglos XVI-XVII, pags. 221-241, Madrid, Castalia, 1992, pág. 230.

9 Biblioteca Serrano Morales (BSM) A-13/215 (87).

10 Biblioteca Nicolau Primitiu (BNP) 849.91/3086 y 849.91/2045.

11 Aguilar Piñal, Romancero popular, pág. 6; Agustín Durán, Romancero general o Colección de romances anteriores al siglo XVIII, Madrid, Atlas, 1849-1851, págs. 268-273; MARCO, Literatura popular, págs. 281-282. 
miento de esta máxima. Nos encontramos por tanto con un relato en el que subyace uno de los temas centrales del discurso moral del siglo XVIII: la regulación de la institución familiar y el papel que en ella correspondía a hombres y a mujeres ${ }^{12}$. Este hecho suma otro argumento al interés que nos sugiere este romance, cuyo contenido exhortaba a su público sobre un tema, el matrimonio y las relaciones entre los sexos, que atañía directamente a su vida cotidiana. Así, Griselda puede invitar a una doble comparación: con los discursos morales (laicos y religiosos) sobre el comportamiento que debían guardar los esposos, y con las prácticas sociales de los lectores y lectoras que se apropiaban del texto.

Para leer en profundidad el romance del siglo XVIII y sopesar las transformaciones argumentales que presenta con respecto a versiones anteriores, conviene en primer lugar hacer un breve repaso «genealógico» del relato partiendo de su origen «boccacciano». La décima jornada del Decameron está dedicada a la magnanimidad de los señores de las antiguas cortes, y para culminarla con un contrapunto sarcástico Dioneo narra la historia de un marqués brutal, que «no hizo ningún acto magnífico, antes se comportó con loca bestialidad» ${ }^{13}$. Desde el mismo comienzo de la historia, su narrador ya informa del tono crítico y mordaz que va a aplicar al relato, que de ningún modo pretende ser ejemplar o moralizante: «lo cual yo no aconsejo hacer a ninguno — apostilla Dioneo-, porque a gran milagro reputo que de tal conducta como la que él tuvo algún bien se viniese a seguir» ${ }^{14}$. La novela cuenta la historia de Gualtero, marqués de Saluzo, quien ha decidido permanecer soltero para no perder su libertad («en lo cual merecía ser tenido por muy sabio» ${ }^{15}$, juzga jocoso el narrador). Sus vasallos, preocupados porque su señor no deje sucesión, le convencen para que tome una esposa, eligiendo Gualtero a una doncella pobre de una aldea cercana, llamada Griselda. Antes de desposarla, el marqués le hace prometer que le será obediente y le complacerá siempre en todo, sin contrariar nunca sus decisiones. Así pues, desnudándola ante sus vasallos, Gualtero despoja a Griselda de sus harapos y la viste con lujosas galas, llevándosela luego a su casa.

12 Sobre la «construcción» de la familia en España durante la época moderna, véase: Isabel MoranT y Mónica Bolufer, Amor, matrimonio y familia. La construcción histórica de la familia moderna, Madrid, Síntesis, 1998; Chartier, Mujeres e Ilustración. La construcción de la feminidad en la España del siglo XVIII, Valencia,

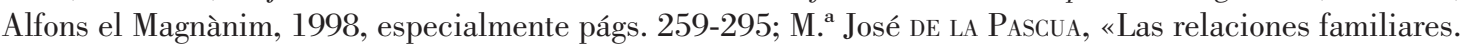
Historias de amor y conflicto», en Morant (dir.), Historia de las mujeres en España y América Latina, Madrid, Cátedra, 2005, vol. II, págs. 287-315.

13 He empleado la edición al castellano de la editorial Planeta: Giovanni Boccaccio, Decamerón, introducción a cargo de Francisco José Alcántara, edición a cargo de Marcial Olivar, Barcelona, Planeta, 1982, pág. 603.

14 Ibid.

15 Boccaccio, Decamerón, pág. 603 
Durante el primer tiempo de matrimonio, Griselda sorprende a cuantos la conocen por su comportamiento ejemplar y virtuoso, que hace enorgullecerse a Gualtero por su decisión: «sin perder nada de su belleza tan gentil mostrábase con todos, y tan placentera y bien acostumbrada, que ninguno hubiera dicho que fuese la hija de Janícolo, guardadora de ovejas, antes que la hija fuese de algún noble señor» ${ }^{16}$. Para colmar la dicha del marqués, al poco tiempo Griselda da a luz una niña.

Sin embargo, Gualtero cambia súbitamente de actitud: «entróle un extraño pensamiento, y éste fue que él quiso probar largamente y con intolerables exigencias, cuál fuese la paciencia de su esposa» ${ }^{17}$. El marqués comienza por hablar a Griselda con duras palabras, mostrándole su descontento por su origen humilde y amenazándola por el malestar que sienten sus vasallos al tener que rendir pleitesía a una pastora. Imperturbable, ella se ofrece solícita a cumplir cualquier decisión que Gualtero tome para acabar con su insatisfacción. El marqués envía entonces a un servidor para que arrebate a su hija de los brazos de Griselda, diciéndole que su señor le ha ordenado matarla, a lo que ella accede sin mudar el rostro, entregando a la niña y pidiendo únicamente al servidor que no deje que las bestias salvajes devoren su cuerpo. Gualtero, complacido por la obediencia de Griselda, envía a su hija a la casa de unos parientes de Bolonia para que la críen en secreto.

$\mathrm{Al}$ poco tiempo el matrimonio vuelve a tener un vástago, esta vez varón, y Gualtero repite el engaño con Griselda, que vuelve a demostrar su complacencia y serenidad ante el mandato de su marido. Los súbditos, creyendo también que el marqués había matado a sus hijos, lo toman por un hombre cruel y se compadecen de la paciente esposa, que no llega a emitir ni siquiera un reproche.

Pasados muchos años, Gualtero decide someter a Griselda a una última prueba: anuncia que el Papa le ha concedido licencia para casarse de nuevo y la despide de su casa para que vuelva a su pobre aldea junto a su padre, llevándose la dote que trajo. Griselda acepta humilde la orden, y desprendiéndose de todas sus galas y alhajas, sólo pide que el marqués le permita regresar cubriendo su cuerpo desnudo (tal y como la tomó Gualtero) con una camisa, «en premio de mi virginidad, con la que yo a vos vine y llevarme no puedo ${ }^{18}$. Él concede esta petición, y ante la desolación de todos los súbditos Griselda regresa a la casa de su padre, donde vuelve a dedicarse a sus habituales tareas de antaño.

Gualtero, entonces, hace venir de Bolonia a sus dos hijos y declara que su futura esposa viene junto a su hermano para celebrar sus bodas. Hace llamar a

\footnotetext{
$16 \quad$ Ibid., pág. 606.

17 Ibid.

18 Boccaccio, Decamerón, pág. 609.
} 
Griselda para ordenarle que adorne su casa y disponga todo lo necesario para el casamiento, a lo que ella se entrega con afán. Cuando llegan los dos jóvenes, Gualtero pregunta a Griselda en presencia de todos qué opina de su nueva esposa, alabando ella su belleza y añadiendo el único atisbo de reproche que asoma en toda la historia: «mas, cuanto puedo, os ruego que aquellas punzadas que disteis a la otra que solía ser vuestra, a ésta no le deis, porque apenas me parece creíble que soportarlas pudiese, ya porque ella es tan joven, o porque ha sido criada y educada entre halagos» ${ }^{19}$.

Gualtero, convencido al fin de la paciencia de su esposa, desvela el engaño al que le ha sometido durante tantos años, «porque yo te quise enseñar cómo debe ser una esposa fiel, y a ellos [sus vasallos] cómo debe escogerse y conservar una esposa» ${ }^{20}$, presentándole a sus hijos, a los que Griselda abraza llorando de alegría. Los festejos son celebrados por todo lo alto, y el gozo, el consuelo y la paz acompañan a los esposos por el resto de sus días.

Dioneo termina su relato criticando las ocurrencias e injurias de Gualtero, «que más merecería puercos guardar que no señorear hombres ${ }^{21}$, y lamentando que el marqués no recibiera su castigo en forma de cuernos, lo que le hubiera estado bien empleado.

Si bien éste es el relato original del que surgieron tantas versiones en la literatura europea, su enorme difusión no partió directamente del Decamerón sino de la traducción al latín que Francesco Petrarca hizo de la novela en 1373, unos veinte años después de la edición de la obra, bajo el título De insigni obedientia et fide uxoria. La versión del poeta laureatus introdujo en el texto tres modificaciones fundamentales que determinarían su diseminación posterior ${ }^{22}$ : el empleo del latín, que aseguraba una difusión eficaz para todo lector culto; la conversión del tono ácido y sarcástico de la novela en otro serio y solemne apropiado para introducir una fábula alegórico-moral; el fondo del relato pasaba a ser en Petrarca un ejemplo para hombres y mujeres de la fidelidad y la constancia que el cristiano debía tener con Dios, que le sometía a pruebas para que tomara conciencia de su propia debilidad ${ }^{23}$. Así lo afirmaba como conclusión: «Mi è parso bene riscrivere ora con altra penna questa novella, per esortare non tanto le nobili donne del nostro tempo ad imitare la sopportazione di questa sposa (mi

\footnotetext{
19 Ibid., pag. 611.

20 Ibid.

$21 \quad$ Ibid., pag. 612.

22 Juan Carlos Conde, «Un aspecto de la recepción del Decamerón en la Península Ibérica, a la sombra de Petrarca. La historia de Griselda», Cuadernos de Filología Italiana, 2001, núm. extraordinario, págs. 351-371.

23 Zuzana Pospísilivová, «Quelques remarques a propos des versions latines d l’histoire de Griselda», en Morabito (ed.), Griselda in Europa, págs. 241-251.
} 
sembra che difficilmente la si possa imitare), quanto i lettori a prendere esempio almeno dalla fermeza di questa donna, perché abbiano la forza di dare al nostro Dio ciò che ella diede al suo uomo» ${ }^{24}$.

Fue esta versión latina de Petrarca el tronco común de la mayoría de traducciones que se difundieron por Europa en los siglos posteriores. Así ocurrió tempranamente en el panorama literario peninsular, pues en 1388 Bernat Metge daba a conocer su traducción al catalán de la novela, «una història la qual recita Petrarca, poeta laureat, en les obres del qual jo he singular afecció» ${ }^{25}$. Sin embargo, Metge imprimió un nuevo sentido a la narración, despojándola de su simbolismo cristiano para presentarla como ejemplo de «pasciència, obediència e amor conjugal» para las mujeres, tal y como afirmaba en su dedicatoria a Isabel de Guimerà: «perquè vós e les altres dones virtuoses prenats eximpli de les coses en aquella contengudes» ${ }^{26}$. Al contrario que el escepticismo de Petrarca ante la posibilidad de imitar el comportamiento de Griselda, Metge perseguía infundir en las mujeres el deseo de emulación, insistiendo por un lado en la veracidad de la historia («suplicant-vos senyora —afirma en la conclusión—, que la dita història vullats creure així com és posada, car així fo allà com dessús és dit, jatsia que alguns menyscreents e viciosos diguen que impossible és que dona del món pogués haver la pasciència e constància que de Griselda és escrita» ${ }^{27}$ ), y citando por otro lado algunos ejemplos de esposas que igualaron a Griselda en virtud, como Porcia, hija de Catón, e Hipsicratea, casada con Mitrídates.

La fama de la historia se difundió en poco tiempo entre la gente, según testimonia el propio Metge años después en su célebre obra, Lo Somni: «la paciència, fortitud e amor conjugal de Griselda, la història de la qual fou per mi de llatí en nostre vulgar transportada, callaré, car tant és notòria, que ja la reciten per enganar les nits en les vetlles e com filen en hivern entorn del foc» ${ }^{28}$. Esta notoriedad fue también conocida por las versiones castellanas, que adoptaron asimismo ese sentido práctido que Metge transmitió a la novela como ejemplo directo para las mujeres; de hecho, el título del primer texto de la literatura castellana que se hace eco de la historia de Griselda, en la segunda mitad del siglo Xv, es bien explícito: Castigos e dotrinas que un sabio daba a sus hijas. El tono ejemplarizante se repite en las siguientes versiones de la novela, que son cons-

24 Hemos utilizado la traducción al italiano de Francesco Petrarca, Opere Latine, a cura di Antonietta Bufano, vol. II, Torino, Unione Tipografico-Editrice Torinese, 1987 [segunda edición], pág. 1337.

25 Bernat Metge, Valter e Griselda. Lo somni, edició a cura de Marta JordÀ, Barcelona, Ediciones 62/Orbis, 1984, pág. 11.

26 Ibid.

27 Metge, Valter e Griselda. Lo somni, pág. 27.

$28 \quad$ Ibid, pág. 114. 
tantes desde entonces: las traducciones del Decamerón que toman sin embargo el relato de Griselda de la fuente petrarquesca (un incunable sevillano de 1496 y cuatro reimpresiones quinientistas) o las adaptaciones de la historia incluídas en colecciones de cuentos como la Suma de todas las crónicas del mundo del valenciano Narcís Viñoles (1510), que es a su vez una traducción castellana del Supplementum chronicarum orbis ab initio mundi de Iacopo Filippo Foresti; la obra El patrañuelo de Joan Timoneda (1567), cuya segunda patraña de las 22 que la integran es una versión de la historia de Griselda; o la Varia Historia de Sanctas e illustres mugeres en todo género de virtudes. Recopilada de varios autores de Juan Pérez de Moya (1583), que incluye también su particular «Griseldes Marquesa de Saluces».

En el siglo XVII el argumento de la novela servirá para que diversos autores publiquen obras en las que alteran y modifican la historia, reelaborando los contenidos a su antojo: es el caso de Pedro Navarro con su Comedia muy exemplar de la Marquesa de Saluzia, llamada Griselda (1603), o del propio Lope de Vega, quien entre 1599 y 1608 escribe su comedia El ejemplo de casadas y prueba de la paciencia, modificando los nombres de los personajes, la ubicación de la historia y el propio desarrollo de la acción, con el fin de añadirle interés dramático ${ }^{29}$.

A partir de la segunda mitad del siglo XviI, la historia de Griselda pasó a imprimirse romanceada en forma de pliego de cordel. Su pervivencia en el romancero es, como afirma Pisonero del Amo, una buena prueba de la popularidad de la leyenda en España ${ }^{30}$, pero sin embargo lo ignoramos todo en cuanto a su datación precisa, su posible autoría, sus fuentes literarias y su intensa difusión impresa. Este desconocimiento contrasta con los estudios pormenorizados que se han dedicado a cada una de las anteriores versiones de Griselda mencionadas, y constituye otro indicio de la pervivencia de esa mezcla de desinterés y desprecio que la literatura de cordel ha inspirado tradicionalmente en la investigación, tal y como dijimos al comienzo de este texto. El breve comentario que Pisonero del Amo dedica al romance de Griselda es buena prueba de esa mirada superficial, pues se limita a resaltar algunos elementos formales del texto (la fluidez rítmica del metro corto, el recurso de la neutralización verbal, las series exclamativas paralelas, etc.), destacando su finalidad emotiva y espectacular (propia de una

29 Para conocer con más detalle la trayectoria de Griselda en la literatura peninsular, véase PISONERO Del Amo, «La paciente Griselda»; Juan Carlos Conde y Víctor Infantes, La historia de Griseldis (c. 1544), Viareggio-Lucca, Mauro Baroni editore, 2000; Conde, «Un aspecto de la recepción del Decamerón». Para las versiones de Timoneda y Lope, Fausto Díaz PADILLA, «Griselda in una commedia di Lope e in una patraña di Juan de Timoneda», en Morabito (ed.), Griselda in Europa, págs. 153-165; Catherine Soriano, «El ejemplo de casadas y prueba de la paciencia de Lope de Vega: estudio comparativo», DICENDA. Cuadernos de Filología Hispánica, núm. 10, Madrid, Edit. Complutense, 1991-1992, págs. 293-326.

30 Pisonero del Amo, ibid, pág. 240. 
narración oral), pero negando cualquier tipo de contenido moralizante o regulador de las conductas: «no hay intención pedagógica ni moral sino sencillamente humana, pues se nos ofrece al hombre en manos del destino, inseguro hasta la resolución final» ${ }^{31}$. Por el contrario, en nuestra opinión, además de su obvia finalidad de entretenimiento y diversión, el romance de Griselda no se limitaba a narrar la historia de la virtuosa protagonista, sino que buscaba inculcar y difundir ese modelo de comportamiento entre las mujeres que nutrían su público, tal y como trataremos de demostrar.

El pliego que hemos trabajado lleva por título Romance trágico de Griselda y Gualtero y pertenece, tal y como informa al final, a la imprenta Laborda, situada en el número 18 de la calle Bolsería de Valencia. Esta imprenta, dirigida por Agustín Laborda y Campo, destacó en Valencia a partir de 1750 por su enorme volumen de producción, constituyéndose en una de las más importantes entre las dedicadas a los pliegos de cordel en toda España, como podemos comprobar fácilmente observando la cantidad de ejemplares salidos de sus prensas que menciona Aguilar Piñal en su compilación de romances del siglo XVIII ${ }^{32}$. Antes de abrir su propio negocio, Agustín Laborda había formado sociedad con el impresor Cosme de Granja, quien como dijimos publicó también un romance de Griselda en la primera mitad del siglo: es muy posible que Laborda conservara uno de los ejemplares y se limitara a reimprimirlo años después.

El impreso se compone de cuatro pliegos en cuarto, con el texto presentado en dos columnas y un único grabado en la primera página, sobre el título, que representa a Griselda y Gualtero aisladamente, sin fondo alguno. En este caso el título no viene acompañado, como es usual, de un breve resumen del argumento, lo que sí se da en otros ejemplares, como los de la imprenta Fausto García Tena (Córdoba) o Santaren (Valladolid): Romance de la peregrina historia de esta pastorcilla, y de cómo el Marqués Gualtero trató su casamiento con ella, y salió el más singular ejemplo de la obediencia que deben tener las mugeres casadas a sus maridos $^{33}$. Es significativo que ya desde este encabezamiento se determina la naturaleza ejemplar del romance y su interpretación; no alude a las crueles pruebas del marqués ni al insólito sometimiento de Griselda, sino que fija la conclusión que debe extraerse de la historia: la obligación de la mujer de obedecer a su marido. El sentido de alegoría cristiana que imprimió Petrarca a la novela

$31 \quad$ Ibid., pág. 241.

32 Aguilar Piñal, Romancero popular, pág. 310. Sobre la imprenta Laborda, véase José Enrique Serrano Morales, Reseña histórica en forma de diccionario de las imprentas que han existido en Valencia desde la introducción del arte tipográfico en España hasta el año 1868, Valencia, 1898-1899, págs. 242-246 y Francisco Almela y Vives, La popular imprenta de Laborda, Valencia, CSIC, 1959.

33 Aguilar Piñal, ibid., pág. 6. 
boccacciana ha desaparecido en el romance (lo que ya vimos que ocurría en la traducción de Metge), aferrado a una lectura literal y prosaica de la leyenda.

La historia está dividida en tres partes (algo muy usual en los romances) que fragmentan el relato en función del tono de la narración: alegre en el primero (boda de Griselda y Gualtero), trágico en el central (pruebas del marqués) y de nuevo alegre en la resolución final. Formalmente, el romance contiene los elementos característicos de este tipo narraciones, muy marcadas por la oralidad y la recitación a la que estaban destinadas: constantes llamadas de atención al público («atiéndame todo el orbe», «préstenme todos silencio», «atención, oyentes míos»), invocación a la Virgen antes de empezar el relato, versos recordatorios al comienzo de cada parte («ya dije con cuántas glorias / con el invicto Gualtero / quedó casada Griselda»), o exclamaciones emotivas ante los acontecimientos («ipero qué gozo, / qué júbilo, qué alabanzas, / qué placeres, qué alegrías!», «iqué tormento!», «ioh, pasmosa maravilla!»).

Sin embargo, dejando de lado el análisis formal, queremos destacar algunos aspectos del texto romanceado que nos hablan significativamente del fondo de la narración, de su sentido subyacente, sobre todo al compararlos con la fuente original, esto es, con el texto de Petrarca, al que el romance sigue con bastante fidelidad. Las modificaciones argumentales, sin referente en ninguna de las traducciones y versiones peninsulares del texto petrarquesco, tal vez puedan ponerse en relación con las transformaciones sociales y culturales de su tiempo: con las expectativas de su público por un lado, y con las posibles intenciones moralizadoras que impulsaban el discurso, por otro.

El análisis individualizado de los dos protagonistas nos ayudará a establecer un orden en nuestra exposición. Comencemos por Gualtero: si bien Petrarca humanizó y suavizó en buena medida la figura del marqués, eliminando la crítica mordaz que en el Decamerón se hacía de su comportamiento, al que tachaba de bestial e inhumano, el tratamiento del personaje en la versión latina era complejo, ambiguo, y no eludía ciertos juicios negativos sobre su actitud. Por el contrario, en el romance ni se suaviza ni se critica la figura del marqués, sino que es representado de modo frío y plano, como situado por encima de cualquier consideración moral.

Ya en la presentación que hacía de Gualtero, Petrarca (así como Metge y los demás traductores a la zaga), tras elogiar sus virtudes (alta cuna, nobleza de costumbres, belleza) censuraba su desinterés por el futuro y su obsesión por la caza, dado que como decía Metge: «totes les altres coses que a fer havia ne menyspreava» ${ }^{34}$. En el romance se muestra sin embargo una visión mucho más

34 Metge, Valter e Griselda, pág. 12. 
indulgente con esta actitud del marqués, sin hacer mención a la despreocupación por el futuro ni a la dejación de sus obligaciones, y tan sólo indicando en este sentido que era «aficionado a la caza, / de tal modo, que por ella / toda diversión dejaba» (la cursiva es nuestra).

Esa representación plana o superficial de Gualtero que como hemos dicho dibuja el pliego, es limitada tanto en la crítica como en la alabanza del personaje, y así, mientras las versiones petrarquescas describen la sabiduría que el marqués demuestra al adivinar la enorme virtud que se esconde en la humilde pastora («virtú straordinaria, superiore al sesso e all' età, che l'umiltà della condizione nascondeva agli occhi del volgo» ${ }^{35}$ ), en el romance no se menciona esta sabiduría, pues Gualtero decide casarse con Griselda tan sólo porque se aficiona «a su gala».

Llegamos así a uno de los momentos centrales del relato, cuando Gualtero hace prometer a Griselda que le obedecerá siempre sin contrariarle jamás, promesa que determinará el desarrollo de la historia. Dada la importancia de la cuestión, sorprende en el pliego el laconismo del marqués, que tan sólo pregunta: «dime, ¿̇ú serás constante / en todo cuanto yo haga?». Brevedad que contrasta con el auténtico interrogatorio al que Gualtero somete a Griselda en las versiones anteriores: incluso en su libérrimo relato, Joan Timoneda se atiene en este fragmento fielmente a Petrarca en cuanto a la minuciosidad de las condiciones que el marqués impone a la pastora para casarse con ella, otorgando importancia mayúscula al momento, sin el cual no se explica el argumento posterior: «pero yo quiero saber de ti una cosa, y es que, cuando nuestro casamiento fuere concluido, el cual será luego, placiendo a Dios, me desengañes si estás pronta para hacer de buena gana todo cuanto yo te mandare, de suerte que nunca vengas contra mi voluntad, y pueda hacer de ti lo que bien me pareciere, sin que por ello conozca en tu cara tristeza, o en tus palabras contradicción alguna» ${ }^{36}$ (la cursiva es nuestra). De esta manera se justifican en la patraña segunda y en las demás versiones petrarquescas el comportamiento de Gualtero y la docilidad extrema de Griselda, que con su promesa queda atada de pies y manos a la voluntad de su marido. Esta necesidad de justificar (en cierta medida) la crueldad de Gualtero no se da tan explícitamente en el romance, que pasa casi de puntillas sobre esta parte del relato. Se podría decir que el autor del pliego no consideró imprescindible dar coherencia a la historia vinculando la actitud desmesurada de Gualtero con el cumplimiento de la palabra dada por Griselda.

35 Petrarca, Opere latine, pág. 1317.

36 Joan Timoneda, El Patrañuelo, edición a cargo de M. a Pilar Cuartero Sancho, Madrid, Austral, 1990, pág. 66. 
El deseo del marqués de probar a su esposa simplemente se da, sin requerir explicación alguna. La frialdad del personaje se muestra también en el romance en la ejecución de las propias pruebas, que aplica sin miramiento alguno expulsando a sus hijos de su casa (en este aspecto el pliego suaviza la orden, que en los textos anteriores era la muerte de los niños). Mientras en Petrarca y sus seguidores, Gualtero expresa a Griselda su dolor por las decisiones que sus vasallos le obligan a tomar («convendrà ' $\mathrm{m}$ fer cosa qui em serà la pus trista $\mathrm{e}$ dolorosa que jo pogués fer» ${ }^{37}$, «cuando pienso en ello, amada Grisélida, no me lo sufre el corazón que tal cosa ponga en efecto» ${ }^{38}$, «los meus vasalls me forcen, e lo Papa hi consent, que jo haja altra muller» ${ }^{39}$ ), en el pliego se muestra implacable al dar sus órdenes («salga tu hija de casa, / y esto ha de ser al momento», «y a tu hijo por lo menos / en ningún tiempo darán / de hijo de marqués respeto; / salga pues luego de casa», "y pues licencia del Papa / para repudiarte tengo, / y mi nueva esposa viene, / tu has de salir sin remedio / de palacio»). La crueldad de Gualtero queda aún más acentuada cuando, una vez desaparecidos sus hijos, se empeña en nombrárselos de cuando en cuando a Griselda para comprobar si ella muestra algún atisbo de pena, detalle que no aparece en ninguna versión anterior.

Es significativo, por último, el indulto absoluto otorgado por el romance a la figura del marqués, cuyos desmanes no reciben a lo largo de los versos ni una sola censura o exclamación de reproche que intente hacer cómplice de la indignación al público, algo muy común en este tipo de literatura. Gualtero aparece así ajeno a cualquier tipo de juicio sobre su comportamiento, libre de cualquier crítica o acusación: incluso se elimina el fragmento de la novela en que los vasallos comienzan a murmurar en contra de su señor, que sí aparece en el Valter e Griselda de Metge («poc a poc se començà escampar mala fama de Valter», «per la qual cosa Valter, qui solis ésser molt car als sotsmesos, fo reputat a les gents per infami e odiós $\left.{ }^{40}\right)$. De este modo, el personaje del marqués, sin crítica ni alabanza, recibe un tratamiento plano, sin profundidad alguna, dedicándose a poner en marcha las acciones que le dicta su capricho.

Entremos ahora en el análisis de la protagonista del romance, Griselda. Podríamos coincidir con lo dicho a propósito de Gualtero sobre la simplificación del personaje, pero en otro sentido: mientras el marqués acaba resultando casi una figura secundaria, sin fondo alguno, Griselda pierde también esa riqueza de matices de la que la dotó Petrarca pero con la finalidad de destacar la virtud

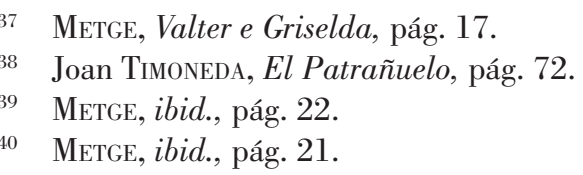


esencial que representa el personaje y que debe ser retenida por el público: la obediencia absoluta a su marido.

Esta simplificación comienza ya con la mera descripción de la virtuosa pastora, a la que Petrarca definía como «notevole per bellezza fisica, ma splendida quant'altre mai per la bellezza dell'animo e dei costumi [...] ignara di ogni forma di piacere, non pensieri effeminati e infantili aveva appresso a nutrire, ma un animo virile e maturo chiudeva nel petto virgineo» ${ }^{41}$. La insistencia sobre «el ánimo viril» de Griselda se repite en los continuadores de Petrarca: «reposava en lo seu pits virginal coratge d' home vell i savi» ${ }^{42}$, afirma Metge, y según Timoneda poseía «un grave y varonil corazón» ${ }^{43}$. El romance, por el contrario, se limita a describir a Griselda como «una honesta muchacha [...] tan bizarra y tan hermosa / que era otra segunda Palas».

La omisión de cualquier virtud de la protagonista más allá de la belleza y de la constancia conyugal se pone aún más de manifiesto en el fragmento que describe su nueva vida tras convertirse en marquesa: aquí Petrarca, en dos largos párrafos, se recreaba describiendo las capacidades innatas de Griselda en el cumplimiento de sus nuevas obligaciones, «tanta era la dignità della vita e dei costumi, tanta l'elevatezza e la dolcezza del parlare ${ }^{44}$, de manera que su fama se extendía más allá de los confines del marquesado, lo que llenaba de orgullo a Gualtero. Pero Petrarca todavía llegaba más lejos, atribuyendo a Griselda ocupaciones públicas en ausencia de su marido, como la resolución de pleitos entre los campesinos o la pacificación de los nobles en discordia, labor que cumplía «ab tanta maturitat e egualtat de juí —añade Metge—, que tothom deïa que Déu los havia tramesa aquesta dona del cel» ${ }^{45}$. Pues bien, esta parte de la novela que alaba la valía y la polivalencia de Griselda, en el romance sencillamente se pasa por alto, desaparece. Para referirse a ese primer tiempo de paz y prosperidad entre los nuevos esposos el pliego emplea tres versos: «dejo aparte la alegría / de los cuatro años primeros / de su feliz matrimonio». La única virtud que no debe «dejarse aparte», el sometimiento de Griselda al capricho de Gualtero, no queda pues ensombrecida por ninguna otra capacidad de la protagonista.

Esa única virtud es puesta de manifiesto una y otra vez mediante las respuestas que la marquesa da a su marido cuando es puesta a prueba. En principio, las palabras con que Griselda expresa en el romance el doblegamiento de su

\footnotetext{
$41 \quad$ Petrarca, Opere latine, pág. 1317.

42 Metge, Valter e Griselda, pág. 14.

3 Timoneda, El Patrañuelo, pág. 64

44 Petrarca, ibid., pág. 1321.

5 Metge, ibid., pág. 17.
} 
voluntad ante las exigencias de Gualtero no difieren de las versiones anteriores, salvo en pequeños (pero en ocasiones significativos) detalles, como la mención a la crianza de los hijos: el pliego insiste en el amoroso amamantamiento de la protagonista a sus hijos («crió Griselda la niña / con gran cariño a sus pechos / por espacio de dos años») mientras Petrarca tan sólo aludía al destetamiento de la niña como marca temporal (a partir de entonces Gualtero pondría en práctica su plan), sin especificar el tiempo que dura la lactancia y ni siquiera que fuera alimentada por su madre. Tal vez esta mención expresa al cariño de Griselda ofreciendo el pecho a sus hijos, inexistente en las otras versiones, estuviera relacionada con el impulso moral que la crianza materna conoció en el siglo XVIII, época de publicación del romance ${ }^{46}$.

Sin embargo, como decíamos, apenas hay variaciones entre el pliego y los textos petrarquescos en las respuestas de Griselda ante las pruebas que se suceden: el sometimiento es absoluto en todas las versiones («haz, dispón, manda y ordena / que yo siempre a tu precepto / estoy firme y dedicada», «señor / ya os dije que mi deseo / y mi mayor alegría / es daros gusto completo»), estando siempre las respuestas acompañadas de gestos afables («con semblante risueño», «festivo y sereno / manifestaba el semblante», «siempre mostrando alegría»). Ahora bien, conforme avanza el relato, encontramos en el romance más acentuada la sumisión de Griselda, con intervenciones creadas de nuevo cuño, inexistentes en las otras narraciones: así, por ejemplo, cuando Gualtero la echa de palacio y Griselda se encamina a casa de su padre cubierta sólo por una camisa y rodeada de gente que llora su desgracia, Petrarca sólo menciona el silencio imperturbable y la ausencia de llanto por parte de Griselda, mientras que el autor del pliego se recrea en el momento, poniendo en su boca palabras de consuelo para la gente y de resignación frente su adversidad:

...no lloréis, pues yo no pierdo cosa alguna propia mía, que en pobreza y desnudez pasé la flor de mi vida; y si tuve esta ventura, la Providencia divina me la dio, para que ahora me sirva de más fatiga:

\author{
no siento el perder las grandes \\ riquezas que poseía; \\ sólo siento el ausentarme \\ del esposo de mi vida: \\ este dolor me atribula, \\ esta pena me fatiga, \\ esta congoja me ofende, \\ y esta aflicción me contrista.
}

46 Sobre el tema de la lactancia, véase Mónica BoLufER, «Actitudes y discursos sobre la maternidad en la España del siglo XvIII, la cuestión de la lactancia», Historia Social, n. ${ }^{\circ}$ 14, otoño 1992, págs. 3-22. 
De este modo el dramatismo de la desgracia de Griselda va in crescendo, acentuando sus tintes trágicos mediante el contraste con su actitud sosegada y paciente, que la asemeja a una santa mártir. El narrador describe el «estruendo de los sollozos y suspiros» de la gente, las «piedras enternecidas» por sus palabras, los vasallos asomados a las ventanas «acompañando el llanto», todo el lamento que rodea a Griselda hasta que llega junto a su padre. En este punto se expresa en el romance el punto álgido de la entrega total de la protagonista para conseguir la felicidad de su esposo, pues ante las palabras recriminatorias de su padre contra Gualtero, responde:

Padre mío de mi vida,
no fui yo la desdichada,
que quien tuvo la desdicha
fue mi esposo, que casó
con una que no valía
tanto como él; esa fue
mi fortuna y su desdicha;
y para aliviar su pena

no obstante de que yo viva permite el Papa otra esposa a mi esposo, porque sirva de paz y quietud a todos: yo vengo con alegría a vuestra casa, señor, aunque tengan fin mis días, como fueron sus principios entre pobreza metida.

Vemos pues cómo una parte del relato secundaria en Petrarca y sus traductores (que se limitan a indicar que el padre de Griselda sospechaba que algo así acabaría sucediendo con su hija, por ser de origen pobre) pasa a convertirse en el pliego en excusa para expresar la humildad sin límites de Griselda y su alegría por lograr con su marcha la felicidad de su esposo, única finalidad de su vida.

Al contrastar el romance con las versiones anteriores se aprecia más claramente la exageración que su autor imprime al comportamiento de Griselda, que acaba constituyendo una caricatura de su personaje. Así, cuando Gualtero la manda llamar para que realice los preparativos de su boda, ella «le mira, / con humildad cariñosa / de esta suerte le decía: / mándame, esposo y señor, / en que humillada te sirva, / que mi gusto es complacerte». Y más aún, cuando el marqués le pregunta su parecer sobre su nueva esposa, Griselda se limita a alabar su belleza y a desear un feliz futuro para ambos; sin embargo, Boccaccio, Petrarca y los demás textos añadían como coletilla ese reproche tamizado que la pastora dirige a Gualtero para que no se porte con su nueva mujer del mismo modo que con la anterior («que aquellas punzadas que disteis a la otra que solía ser vuestra, a ésta no le deis» $\left.{ }^{47}\right)$. En el romance queda eliminada esta apostilla, este único

47 Boccaccio, Decamerón, pág. 611. 
atisbo de recriminación de la novela de Boccaccio, como si se quisiera evitar la más mínima duda sobre la sincera y complacida obediencia de Griselda.

En cuanto al desenlace de la historia, es llamativo que tras la explicación de Gualtero sobre las pruebas superadas por su esposa y sobre los fines que perseguía («pues si fue una acción impía / mostrar con ella despego, / fue alarde con que quería / acrisolar su constancia»), no se hace mención en el romance a la reacción de Griselda, que en las versiones petrarquescas sí se deshace en lágrimas, abraza a sus hijos y es vestida con galas para celebrar su retorno. Nada de esto dice el pliego, que enlaza las explicaciones de Gualtero con unos versos que expresan la alegría de la corte (con una incoherencia argumental incluida, pues afirma que para la fiesta llevaron a palacio a los padres de Griselda, cuando en ningún momento se ha mencionado a su madre). Parece como si, una vez que la protagonista ha cumplido con su virtuoso deber, el autor del romance no hubiera considerado necesario describir su reacción cuando sale definitivamente airosa de la dura prueba: lo dicho bastaba para inculcar su ejemplo.

Así lo expresa la inmediata conclusión del pliego, que apelaba directamente a las mujeres como interlocutoras preferentes ante la historia narrada: «ea, señoras mujeres, / pues os presento a la vista / este espejo de Griselda, / tomad de él ejemplar vida». Dada la claridad de la exhortación, parece disparatado negar al romance una intención moralizadora, una finalidad de regulación de las costumbres a través de la difusión de este «espejo» de obediencia y entrega marital. La historia se dirigía principalmente a las mujeres, aunque el narrador añadía también una tímida recomendación a los maridos para que no imitaran el comportamiento de Gualtero ni maltratasen a sus esposas («no es decir que los hombres, /a fuerza de la codicia / de ser dueños, se adelanten / a querer ser homicidas»), justificando esta benevolencia con el endeble argumento bíblico de que la mujer fue creada del costado del hombre, esto es, cerca de su corazón. No obstante, la mención al Génesis le servía al narrador para recordar a las mujeres el mandato divino de sujeción al marido: «que fue la mujer primera / formada de una costilla, / para darnos a entender / la inmensa Sabiduría, / que la mujer no es cabeza, / sino amable compañía». A pesar de todo lo narrado, convenía enfatizar en la conclusión el puesto sumiso que le correspondía a la esposa en la relación conyugal, y al constatar esta insistencia se comprende que el autor del romance no viera conveniente hacer mención alguna a las capacidades y funciones públicas que Petrarca atribuía a Griselda.

Para finalizar la conclusión, el narrador exhortaba a los casados a compartir una vida apacible, una vez que cada uno había asumido su función: «y así / debe ser muy excesiva / la paz y unión entre ambos, / siempre tan de asiento y fija, / como la ley de Dios manda, / y la Iglesia nos lo avisa». En estos últimos 
versos se hacía alusión, como vemos, a la indisolubilidad del vínculo conyugal («unión siempre tan de asiento y fija») apelando a la doctrina católica y a la ley de Dios, que sin embargo no eran mencionadas en ningún otro momento del texto como inspiración del comportamiento de Griselda. Podríamos decir que el relato constituía casi un «sermón profano» que difundía, llevándolos al extremo, esos principios de sacrificio y abnegación propuestos para las mujeres por la literatura religiosa tradicional, cuyo discurso estaba determinado por una imagen de la mujer como un ser quebrantado y lleno de vicios, imagen que bebía de la secular tradición misógina. El romance de Griselda podría añadirse al conjunto de discursos religiosos de los que hablan Morant y Bolufer cuando afirman: «los textos morales, instrucciones para casadas, sermones y vidas de santas les hablaban en el lenguaje del deber, las exhortaban a forzarse a sí mismas para violentar una naturaleza que consideraban intrínsecamente perversa, y llamaban a sus padres y maridos a vigilarlas y obligarlas a recorrer el camino de la salvación» ${ }^{48}$.

Con todo, si bien es cierto que la historia de Griselda se amoldaba a este modelo femenino defendido desde el púlpito, su conversión al romance exageró los contenidos y construyó un relato de extremos cercano al esperpento: a la crueldad completamente insensible de Gualtero se oponía la obediencia y ciega sumisión de Griselda, constituyendo dos personajes desproporcionados y grotescos, aumentados por una lente deformante. En nuestra opinión, esta exageración no era sólo fruto de las exigencias del género literario, que dada su difusión oral precisaba de contenidos impactantes y simplificados, sino que buscaba también que el mensaje moral quedara claro entre el público, especialmente femenino en este caso. La base de esta afirmación está constituida por el conjunto de romances que a lo largo del siglo XVIII y con diversas estrategias difundieron ese exagerado modelo de sumisión femenina que ejemplifica Griselda. Todos ellos comparten el patetismo y la desmesura a los que nos hemos referido.

Por un lado, encontramos romances protagonizados por esposas virtuosas, caracterizadas por su paciencia y resignación ante la adversidad y por su devota obediencia al marido. Son muchos los argumentos que se basan en el sumiso acatamiento por parte de la esposa de un castigo injusto impuesto por su marido, víctima de un engaño o calumnia. Así, por ejemplo, en el romance de Don Claudio y doña Margarita, Claudio ordena la muerte de su virtuosa esposa, calumniada por el mayordomo de la casa, pero la dulce sumisión que ella demuestra compadece a sus verdugos que le perdonan la vida. La trama se repite en Don Juan de Lara y doña Laura, en el que Laura no emite una queja cuando su esposo se dispone a acuchillarla porque cree que es infiel. En ocasiones el castigo no

48 Isabel Morant y Mónica Bolufer, Amor, matrimonio y familia, pág. 50. 
es la muerte, sino el abandono, como en Agustín de Guevara y María Javiera, de Jerez, romance en el que el demonio engaña a Agustín diciéndole que su esposa le engaña, de modo que él se marcha a América dejando a María Javiera con tres hijos que alimentar. Arruinada, sobrevive estoicamente pidiendo limosna, hasta que la intervención divina saca a Agustín del engaño. La actitud de conformidad y de renuncia se lleva al extremo en el romance de Don Carlos y doña Laura: en este caso es una mujer quien, enamorada de Carlos, le convence de que su esposa le es infiel. Él castiga a Laura enterrándola en un hoyo hasta la cintura y ordenando que no se le dé alimento ni bebida. Ella no emite ni una queja, pero logra sobrevivir gracias a las viandas que le pasa una fiel criada. Carlos, por su parte, se casa con la mujer que ha urdido el engaño y ambos se divierten mortificando a la indefensa Laura, que soporta con sacrificio las injurias: «sus mayores deleites / y su mayor desvergüenza / era ir adonde estaba / la ya su esposa primera / y ambos a dos la escupían / la ultrajan, la desprecian». Finalmente, Carlos descubre la verdad y desentierra a Laura pidiéndole su perdón, que «ella atenta / genéricamente ha dado / con voluntad muy perfecta» ${ }^{49}$.

Como vemos, ideas como el perdón ante los desmanes del marido, el acatamiento de su voluntad y la resignación ante la injusticia eran trasmitidas en este tipo de relatos junto a sus dramáticas historias, en las que (al igual que en el romance de Griselda) las protagonistas parecían convertirse en santas mártires sufriendo el tormento a causa de su fe. En efecto, los pliegos hagiográficos mostraban unas imágenes de mujeres que, en forma y contenido, se aproximaban mucho a las de estas esposas ejemplares, de manera que apenas encontramos diferencias en el tratamiento de unas y otras. Así lo vemos en el romance de Santa Genoveva, princesa de Brabante, quien a pesar de preferir el retiro y la oración se casa con el conde Palatino Sigifredo, por contentar a sus padres. Su historia es muy parecida a cualquiera de las que acabamos de ver: Sigifredo es engañado por su mayordomo y castiga a Genoveva, que acepta sus penalidades como voluntad de Dios y de su marido. El discurso que pronuncia cuando la llevan al monte para darle muerte podría ponerse en boca de cualquiera de esas esposas ejemplares, y muy en concreto recuerda a las palabras de Griselda cuando es echada de palacio por Gualtero:

$\begin{array}{ll}\text { Aquí enmudece la lengua, } & \text { adiós, montes, adiós, selvas, } \\ \text { aquí faltan los sentidos } & \text { adiós, Patria amada mía } \\ \text { y el corazón titubea, } & \text { adiós, amigos, que es fuerza }\end{array}$

49 Todos son pliegos procedentes de la Biblioteca Serrano Morales: A-13/256 (64), A-13/215 (46), A-13/215 (39), A-13/257 (40-41). 
al oír el dulce llanto,

los suspiros y las quexas

con que amante se despide

de su casa Genoveva:

«adiós, vasallos, decía obedecer a mi esposo;

llorad tristes mis exequias,

y sedme fieles testigos

que mantuve la firmeza

que a tal esposo debía».

También el romance de santa Rita de Cassia se refiere a la sumisión al marido como virtud de la santa, por mezquino y ruin que sea el comportamiento de éste. Aunque santa Rita desea desde pequeña que sus padres la metan en un monasterio, éstos conciertan su matrimonio para que dé sucesión a la familia y eligen como esposo a un hombre que resulta ser «una fiera»:

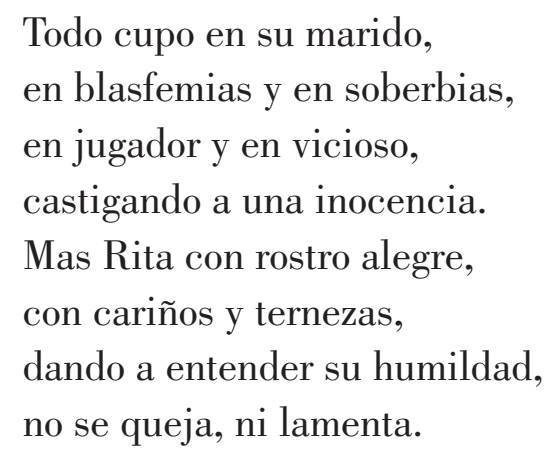

En definitiva, estas santas aceptaban los males que les sobrevenían como pruebas permitidas por Dios para «acrisolar su constancia» (por utilizar las palabras de Gualtero), como cuenta el romance de Santa Rosalía de Palermo, que es elegida por Dios como esposa y sometida a un sinfín de penalidades y sufrimientos a través de los cuales ella demuestra su entrega absoluta ${ }^{50}$. Es sorprendente el paralelismo que se puede establecer entre esta santa y la paciente Griselda, puestas ambas a prueba por sus respectivos legítimos superiores para demostrar su amor conyugal (terrenal o místico). Gualtero (y los maridos de los pliegos referidos) pueden ser tomados como símbolos de Dios, del cual deben aceptarse los bienes y los males como pruebas de humildad. Desde esta perspectiva se comprende mejor la eliminación de toda crítica sobre el comportamiento de Gualtero en el romance, que presentaba sus decisiones como provenientes de lo alto. El pliego ha retomado así, de modo involuntario, el contenido trascendente que Petrarca imprimió a la novela de Boccaccio, tomándola como una alegoría de la relación entre Dios (Gualtero) y el cristiano (Griselda), pero paradójicamente,

50 Estos y otros muchos pliegos hagiográficos pueden consultarse en la Biblioteca Nicolau Primitiu, XVIII/1104 (92), XVIII/1104 (94), XVIII/1104 (95-97). 
el empleo de ese idealismo sirve para reforzar el mensaje terrenal que el texto del siglo XVIII pretendía inculcar en las mujeres.

Los romances (profanos o hagiográficos) no eran el único medio por el cual se predicaban las virtudes de la buena esposa, a través de su ejemplo. Junto a las historias de Griselda o María Javiera, los ciegos vendían también pliegos en los que se daban instrucciones o recetas directas a las mujeres, normas de comportamiento para ejercer dentro del matrimonio. Queremos destacar dos textos significativos, por un lado la Receta utilísima para curar los males de las mujeres mal casadas o que tienen malos maridos, impreso por Laborda, y por otro el Romanç nou, molt graciós i entretengut, on se refereixen, al peu de la lletra, totes les cosetes que han de previndre les senyoretes per a parir, escrito en forma de col.loqui por Carles Ros y fechado en 1736, sin pie de imprenta, del cual existen varias reimpresiones ${ }^{51}$.

La Receta utilísima se dirige a la mujer que se siente «del marido aborrecida, mal querida y peor tratada», dándole consejos para que le ame «con tierno cariño y santa / amistad, tan verdadera / que no le agravies en nada». La minuciosidad de las instrucciones abarca todos los aspectos de la vida diaria: debe mitigar los disgustos de su marido con su gracia, no replicarle ni mostrarse altiva, no separar «mesa y cama / porque con sólo esta chispa / podrá encenderse la llama», tener paciencia cuando él se enoje, esperarle levantada si es jugador o tiene una amante y regresa tarde a casa para que sienta lástima por ella, no quejarse nunca del maltrato (en todo caso, decírselo al confesor o a sus suegros, nunca a sus padres), hablar bien de él en su ausencia, no salir de casa si él así lo quiere, no tratar con ningún hombre, no preguntarle sobre lo que hace («porque no es de tu inspección / averiguar lo que haga»), etc. Todo ello para que sus virtudes fueran reconocidas por su marido, cuyas maneras bruscas y rudas acabarían amansándose, tal y como afirma la conclusión del texto:

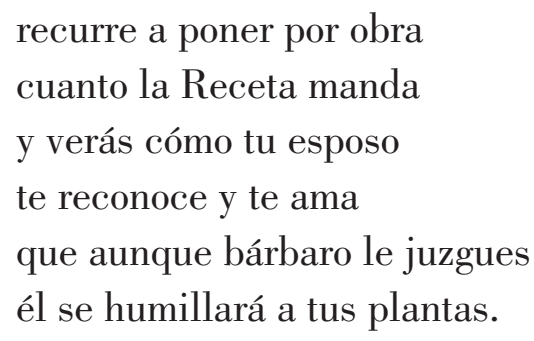

En el caso del texto de Carles Ros, su interés inicial es dar instrucciones a las embarazadas para que preparen todo lo necesario antes del parto (compra

$51 \quad$ BSM A-13/215 (107), BNP 849.91/3086. 
de útiles necesarios, limosnas en el Convento de la Merced para que «toquen a partera», elección de padrinos adinerados, etc.), pero al final el autor incluye una serie de consejos a las mujeres encargándoles «molt seriosament» la paciencia necesaria para aguantar «la gran creu pesada del matrimoni» y lo sujetas que deben estar al marido: si es malo tiene que decirle que es hombre de bien, si es «dropo» que es honrado, debe obedecerle cuando le ordena que no salga, alegrarle cuando está triste, no replicarle si grita, etc. Tras la retahíla, tres versos dirigidos a los hombres, recordándoles que están obligados a mantener a sus esposas con gran decencia, porque se lo merecen (de nuevo hallamos la enorme desproporción entre los deberes atribuidos a hombres y mujeres en el matrimonio).

Como vemos, romances de buenas esposas, vidas de santas y consejos conyugales constituyeron en el siglo XVIII un considerable conjunto de textos populares que difundieron un modelo de virtud femenina que consistía en la devota sumisión a la voluntad del marido. Este modelo conyugal contrastó en la época con el ideal ilustrado de la familia sentimental que fue consolidándose en la segunda mitad de la centuria (opuesto al sometimiento pasivo de la esposa frente al marido, defensor del cumplimiento por parte de ambos cónyuges de una serie de obligaciones —eso sí, desiguales — para el funcionamiento de esa «encantadora sociedad», impulsor del desarrollo de la que suponía «auténtica naturaleza» de la mujer, sensible y doméstica, etc.), cuyos principios chocaban frontalmente por los difundidos a través de los romances ${ }^{52}$. Ignoramos si éstos respondían a una estrategia consciente de moralistas y hombres de Iglesia para hacer llegar sus ideas y doctrinas al pueblo (del mismo modo que se imprimían novenas, aleluyas, relatos bíblicos y explicaciones teológicas), o si sencillamente su discurso bebía de una moral tradicional generalizada en aquella época. El hecho es que esos pliegos se cantaron y vendieron por las calles y fueron escuchados y demandados por un público amplio, que se apropiaría de ellos de maneras diversas, tal vez amoldando su comportamiento a las virtudes que propugnaban, quizá haciendo burla de sus ingenuos contenidos, o sencillamente ignorándolos.

El romance de Griselda era uno de estos impresos colgados de los puestos callejeros. Contemplar el camino recorrido por esta leyenda desde su aparición en el siglo XIV hasta su inclusión en el romancero resulta muy útil para seguir aprendiendo las posibilidades de uso y de resignificación de las que puede ser objeto un texto a través de géneros literarios y épocas sucesivas. Nada queda en

52 Sobre la construcción del modelo de feminidad doméstica y sensible, véase BoLufER, Mujeres e Ilustración; «Transformaciones culturales. Luces y sombras», en Morant, Historia de las mujeres, págs. 479-510; Morant y Bolufer, Amor, matrimonio y familia, págs. 191-240. 
el pliego del siglo XVIII del sarcasmo y la ácida crítica que Boccaccio aplicó al comportamiento de Gualtero, ni tampoco de la alegoría cristiana que construyó Petrarca a partir de la novela original. El romance transformó la historia boccacciana en un relato gazmoño e ingenuo, alejado de la excelencia de Metge o del relato cortés de Timoneda, que trataba de inculcar el desmesurado ejemplo de Griselda a las mujeres con un retrato grotesco de la relación desigual entre los sexos. Condición masculina y condición femenina se reflejaban así en un espejo deformante, a través del cual adquirían tintes esperpénticos.

Pliegos de cordel empleados

Don Carlos y doña Laura. Refierense los ragicos sucessos, que por una Comadre passaron, y el dichoso fin que tuvieron. Compuestos por el Maestro Manuel Diaz. [2 partes, Imprenta Laborda, s.a.] BSM A-13/257 (40-41).

Nuevo y curioso romance de don Claudio y doña Margarita. Dáse cuenta por estenso de lo que sucedió á una principal señora, que por no querer condescender á la ofensa que solicitaba el mayordomo de su casa, éste le levantó un falso testimonio, por el cual padeció muchos trabajos; como lo verá el curioso lector. [2 partes, Imprenta de Laborda, s. a.] BSM A-13/256 (64-65).

Nuevo y curioso romance, en el cual se declara los prodigiosos milagros que en la ciudad de Lisboa ha obrado el glorioso San Antonio de Padua, con un Caballero y una Señora, devotos suyos. Con todo lo demás que verá el curioso lector. [Imprenta Laborda, s.a.] BSM A-13/215 (46).

Receta utilísima para curar los males que padecen las mugeres mal casadas, ó que tienen los maridos malos. [Imprenta Laborda, s.a.] BSM A-13/215 (107).

Romanç nou, molt graciós, y entretengut, hon es refereixen, al peu de la lletra, totes les cosetes que deuen previndre les senyoretes pera parir, la sutjecció que han de tindre al marit, y altres circunstancies que han de guardar les casades, com vorá el curiòs, en aquest any 1736. Dictat per una musa lapèra. [s.i., por Carles Ros Hebrer], BNP. 849.91/3086.

Romance de la peregrina historia, y trágica vida de la penitente anacoreta la Princesa de Brabante Santa Genoveva, sacada de la vida que anda impresa de la misma santa. [ 2 partes, Imprenta Laborda, s.a.] BNP XVIII/1104 (92-93).

Romance de la prodigiosa vida y penitencia de la gloriosa Santa Rosalía de Palermo, Abogada contra la Peste; y lo demás que verá el curioso Lector. [3 partes, Imprenta Laborda, s.a.] BNP XVIII/1104 (95-97).

Romance de la vida, y muerte de Santa Rita de Cassia. [Imprenta Laborda, s.a.] BNP XVIII/1104 (94). 
Romance nuevo de Agustín de Guevara, y el portentoso hallazgo del doblon. Decláranse los mas notables sucesos que le sucedieron á este caballero, natural de Jerez; y la calumnia que contra su esposa le impuso el demonio, saliendo de todo libres por intercesión de San Antonio de Padua. [Imprenta Laborda, s.a., por Pedro Sánchez] BSM A-13/215 (39).

Romance tragico de Griselda y Gualtero. [3 partes, Imprenta Laborda, s.a.] BSM A-13/215 (87). 